\title{
LETTERS
}

\section{Canadian program directors lack data to select residency candidates}

I share the concerns expressed in Dr. Persad's letter. ${ }^{1}$ I supervised nine Canadian Resident Matching Service (CaRMS) matches as diagnostic radiology residency program director in Ottawa, and it was obvious that the lack of objective data with which to evaluate candidates is at the crux of a deeply flawed system. Good research ${ }^{2}$ has identified that objective data (medical school marks or examinations) are the only reliable indicators of success in residency. Canadian program directors presently have no objective data to use to select candidates. We are, as far as I am aware, the only system in the world that has both an entirely pass-fail system and a lack of standardized examinations (the Licentiate of the Medical Council of Canada [LMCC] examination is done after CaRMS).

This frustration from students (subjective and vague criteria) and program directors (lack of useful data points) comes up year after year. ${ }^{3}$ Until Canadian medical schools and the MCC rectify this by moving the LMCC to the third year (for a four-year program), or return to an objective, marks-based evaluation system, these frustrations will not subside.

\section{Matthew D. McInnes MD}

Associate professor of radiology and epidemiology, University of Ottawa, Ottawa, Ont.; The Ottawa Hospital Research Institute, Ottawa, Ont.

Cite as: CMAJ 2018 September 17; 190:E1114. doi: 10.1503/cmaj.69695

\section{References}

1. Persad A. A Canadian medical graduate's views on resident matching. CMAJ 2018;190:E443.

2. Kenny S, Mclnnes M, Singh V. Associations between residency selection strategies and doctor performance: a meta-analysis. Med Educ 2013;47:790-800.

3. Mclnnes M. Residency matching woes. CMAJ 2015; 187:357.

Competing interests: None declared. 